\title{
COUPLED WAVE-BED DYNAMICS, ATCHAFALAYA SHELF, LOUISIANA
}

\author{
Cihan Sahin ${ }^{1}$, Ilgar Safak ${ }^{2}$ and Alexandru Sheremet ${ }^{1}$
}

\begin{abstract}
Observations of waves, currents, suspended sediment concentration and acoustic backscatter are used to reinvestigate the interaction between the combined wave-current flow and cohesive sediments on the muddy Atchafalaya inner shelf. Observations support the previously proposed bed reworking cycle by waves of mobilization and resuspension of bed sediment, erosion, deposition with fluid mud formation and consolidation. Suspended sediment concentration profiles are estimated based on the acoustic backscatter of a current profiler. A onedimensional vertical bottom boundary model is used to reconstruct the vertical structure of the flow characteristics, and estimate parameters difficult to observe directly, such as bottom shear stress. Estimated bed position, concentration profiles and computed bottom stresses remarkably support the previous findings on the bottom stressresuspension relation, critical shear stress for erosion and bed density variation throughout a storm.
\end{abstract}

Keywords: bed reworking; cohesive sediment; muddy clinoform; ocean waves

\section{INTRODUCTION}

Interaction between turbulent flow and cohesive sediment processes is strong in muddy environments (e.g., Traykovski et al. 2007, Jaramillo et al. 2009, Allison et al. 2000, Safak et al. 2010, Sheremet et al. 2011, Sahin et al. 2012, Safak et al. under review and many others). During energetic events, waves and currents may induce bulk stresses exceeding the yield threshold and soften the muddy bed, mobilize and resuspend sediment which then settles at the end of the storm. Since pore pressure increases and sediment matrix is broken, near-bed fluid mud layers of high concentration form which then contribute to wave dissipation (Allison et al. 2000, Sheremet et al. 2011, Safak et al. under review).

The wide and shallow (maximum slope is 1:1000) muddy Atchafalaya subaqueous clinoform has been the focus of several studies over the last decade (Allison et al. 2000, Sheremet and Stone 2003, Sheremet et. al 2005, Kineke et al. 2006, Jaramillo et al. 2009, Safak et al. 2010, Sheremet et al. 2011). The results of these studies, mostly based on optical point measurements of suspended sediment concentrations (SSC) and acoustic measurements of bed position and flow velocities (single point measurements or vertical profiles), suggest that the bed state follows a predictable bed reworking cycle of dilation due to fluidization, sediment resuspension, leading to bed erosion, deposition with fluid mud formation, and eventually to dewatering and consolidation.

Recent study by Sahin et al. (2012) represented an effort to assemble the observations of flow velocities, SSC, and sea-bed position into a more clear picture of wave-current-sediment interaction on the Atchafalaya Shelf. An important improvement in that study over the previous ones was the conversion of backscatter intensity of an acoustic profiler to vertical SSC profiles. This allowed for a check for the vertical mass balance between the sea-floor and the water column in order to investigate the relative importance of sediment resuspension to advection of the material brought by the Atchafalaya River. Also, based on the vertical mass balance, evolution of the bed density during a storm was roughly estimated to vary within the range of $1,030 \mathrm{~kg} / \mathrm{m}^{3}$ to $1,200 \mathrm{~kg} / \mathrm{m}^{3}$. As it might be expected, bed density estimates showed an increasing trend during erosion phase and decreased during deposition, then at the end of the storm, showed a consistent increasing trend during hindered settling and exceeded the space-filling value during consolidation. Another effort was constraining a onedimensional vertical (1DV) bottom boundary layer model for cohesive beds (Hsu et al. 2009) with vertical distributions of SSC and flow velocity measurements in order to obtain bed shear stresses throughout the storm which cannot be observed directly. Interpretation of bed shear stress estimates together with the evolution of approximate sea floor position revealed that sediment resuspension is strongly controlled by variation of bed shear stress, and the critical erosion threshold is in the range of $0.3 \mathrm{~Pa}$ to $0.5 \mathrm{~Pa}$.

This paper investigates the interaction between muddy sea floors and hydrodynamics using a similar approach with Sahin et al. (2012), this time for different storm conditions at same water depth in order to compare the previous results. Suspended sediment concentration (SSC) is estimated based on

\footnotetext{
${ }^{1}$ Department of Civil and Coastal Engineering, University of Florida, 365 Weil Hall, Gainesville, Florida, 32611, USA

${ }^{2}$ Department of Environmental Sciences, University of Virginia, Clark Hall, 291 McCormick Road, Charlottesville,

Virginia, 22904, USA
} 
PC-ADP (Pulse-Coherent Acoustic Doppler Profiler, Sontek/YSI) backscatter. The 1DV model of Hsu et al. (2009) is calibrated using suspended sediment concentration estimates and wave-current measurements to estimate the bottom stresses. Results are expected to constitute a step toward building a more general model of the interaction between near-bed hydrodynamics and muddy seafloors.

\section{FIELD EXPERIMENT}

\section{Site and Instrumentation}

The data set presented here was collected near the 4-m isobath between February 26th and February 28th, 2008 on the muddy inner shelf fronting the Atchafalaya Bay, Louisiana (Fig. 1a). The location and instrumentation are the same with the ones presented in Sahin et al. (2012). A schematic of the platform with the locations of the instruments is shown in Fig. $1 \mathrm{~b}$.


Figure 1. (a) The approximate distribution of the surficial sediments on the Atchafalaya Shelf. The circle marks the location of the instrumented platform $\left(29.26^{\circ}\right.$ latitude North, $91.57^{\circ}$ longitude West). (b) The positions of the instruments deployed with respect to the bed. For point measurements, the location of the sampling volume is marked by a circle. For profilers, arrow indicates the direction of the acoustic signal.

The instrumentation set comprised a downward-pointing PC-ADP, an upward-pointing ADCP (Acoustic Doppler Current Profiler, $1200 \mathrm{kHz}$, Teledyne RD Instruments), an OBS-3 (Optical Backscatterance Sensor, D\&A instruments), an OBS-5 (D\&A instruments) and a Seabird MicroCAT. The PC-ADP sampled near-bed current velocities and backscatter profiles at 2-Hz in 27 bins of $3.2 \mathrm{~cm}$ following a $30 \mathrm{~cm}$ blanking distance. Direct SSC observations were provided by the OBS-5 that recorded 2-min averages of turbidity, and the OBS-3 sampling synchronously with the PC-ADP. The $\mathrm{ADCP}$ measured waves and currents in 20-cm bins with the lowest bin located in 2 meters above bed at 2-Hz in 40-min. bursts every hour. A Seabird MicroCAT at $55 \mathrm{cmab}$ sampled salinity and temperature synchronously with the PC-ADP. Directional wave spectra were obtained with a frequency resolution of $0.0078 \mathrm{~Hz}$ and angular resolution of 4 degrees.

\section{Observations}

The storm investigated took place in late February at the same observation location with the storm discussed in Sahin et al. (2012). The storm started when westerly winds changed to northerly (not shown here) on February 26th at 12:00 hours. Seas reaching almost 1-m height were produced by the storm. The energy of swell was insignificant throughout the storm. With decreasing wind speed, significant wave height dropped to about 0.1-m at the end of the storm (Fig. 2a).

The PC-ADP captured three significant current pulses first two of which took place on early February 27th flowing towards SSW. The third stronger current pulse flowing towards east started about 5 -hrs after the second one weakened, on February 27th at 10:00 hours. During this 5-hrs weakcurrent period between the second and the third pulses, the direction changed slowly from easterly to westerly (Figs. $2 b$ and 2c). During the first two pulses, significant drop in temperature and salinity, and 
increase in SSC were observed suggesting a fast fresh water, likely sediment-loaded, income to the experimental site (Figs. 2d and 2e). After February 27th at 10:00 hours, with the start of current direction change slowly to westerly, the temperature and salinity values started increasing, SSC started decreasing. During the peak of the third pulse on the same day at 12:00 hours, SSC values increased significantly again, probably as a result of local resuspension due to increasing bottom stress induced by high current speed.
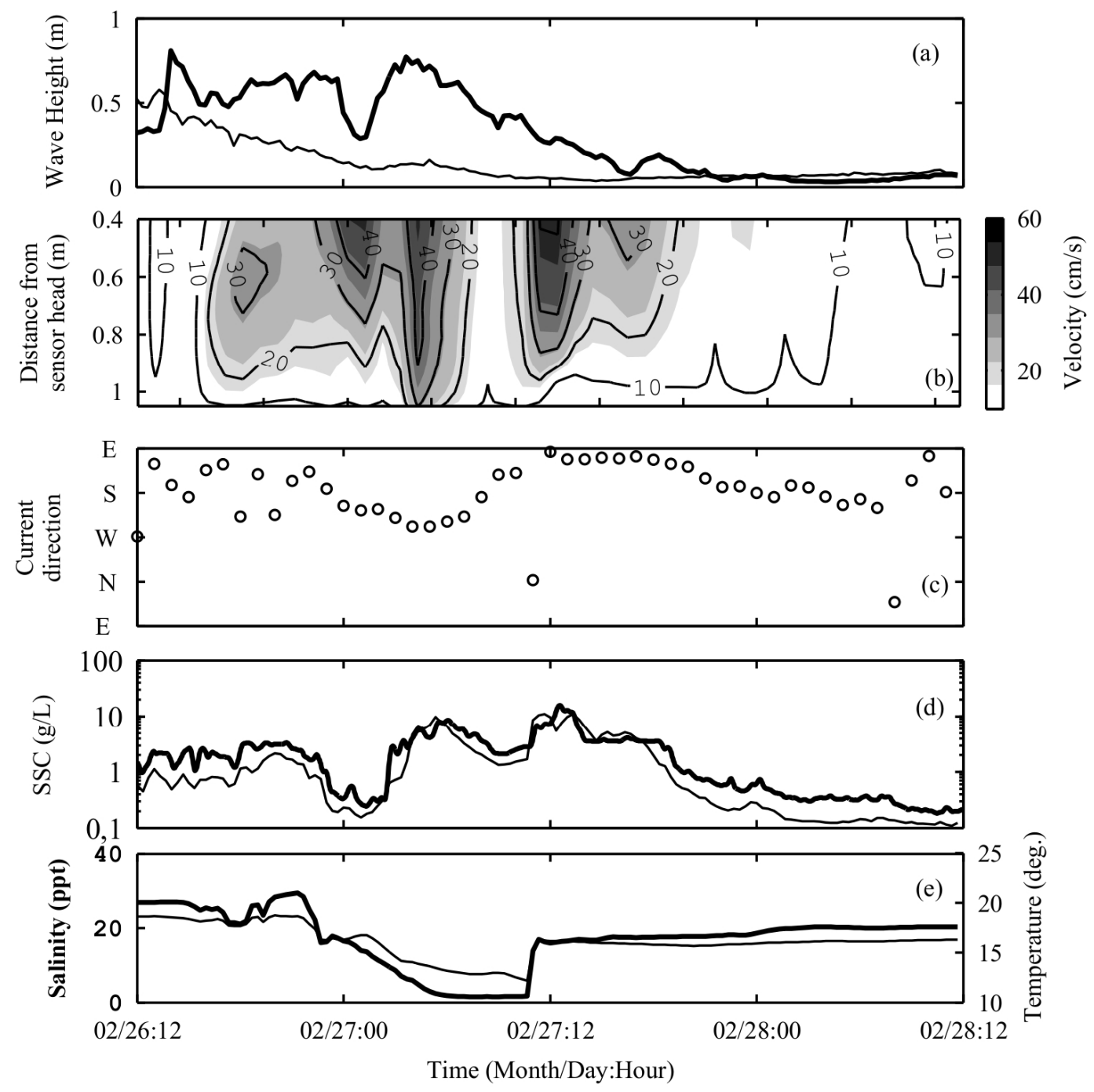

Figure 2. Storm of February 26th to 28th: (a) Significant wave height (short-wave: thick line, swell: thin line). (b) Vertical structure of mean current recorded by the PC-ADP. (c) Direction of PC-ADP mean currents. (d) SSC observed by the OBSs located at $18 \mathrm{cmab}$ (thin line) and $10 \mathrm{cmab}$ (thick line). (e) Salinity (thick line) and temperature (thin line) at $55 \mathrm{cmab}$. Locations of the instruments are shown in Fig. 1b. In the direction convention used, the direction indicated is the direction of the flow (e.g., $\mathrm{N}$ means flowing northward).

The focus in the rest of this study will be the one-day period on February 27th with strongest waves and currents, and highest concentrations measured. The sea-floor showed a similar response to wave and current action to that observed by Sahin et al. (2012). Because strong reflections are typically associated with sharp density gradients, the position of the bed is estimated here as the approximate position of the near-bed local backscatter maximum (black area in Fig. 3b). Following the increase in wave energy and current speed in the morning of February 27th, the bed level falls for about 4 hours between 01:00 hours -05:00 hours (erosion). Bed accretion (deposition) starts following the decrease in current speed until the start of the third strong current event at 10:00 hours which again caused a significant resuspension of the bed sediment (see the high bacscatter intensity values in the water 
column). With the end of the third current pulse and decreasing wave energy, the water column becomes almost sediment-free (low backscatter intensity) suggesting a settling and deposition of sediment after Febrauary 27th at 21:00 hours. The bed position was recorded at about 4-cm above its initial position at the end of the storm indicating a formation of a layer of fluid-mud and consolidation. These interpretations are in agreement with the previous observations (Sahin et al. 2012) that the evolution of the seafloor throughout a one-day storm event goes through the following cycle: mobilization and resuspension of bed sediment through possible liquefaction and erosion, which is followed by settling (fluid mud formation) and consolidation as wave energy decays. The only difference from the previous studies is that bed dilation was not observed in the beginning of the storm. The fact that the bed did not dilate here could be attributed to relatively low swell energy throughout the storm.
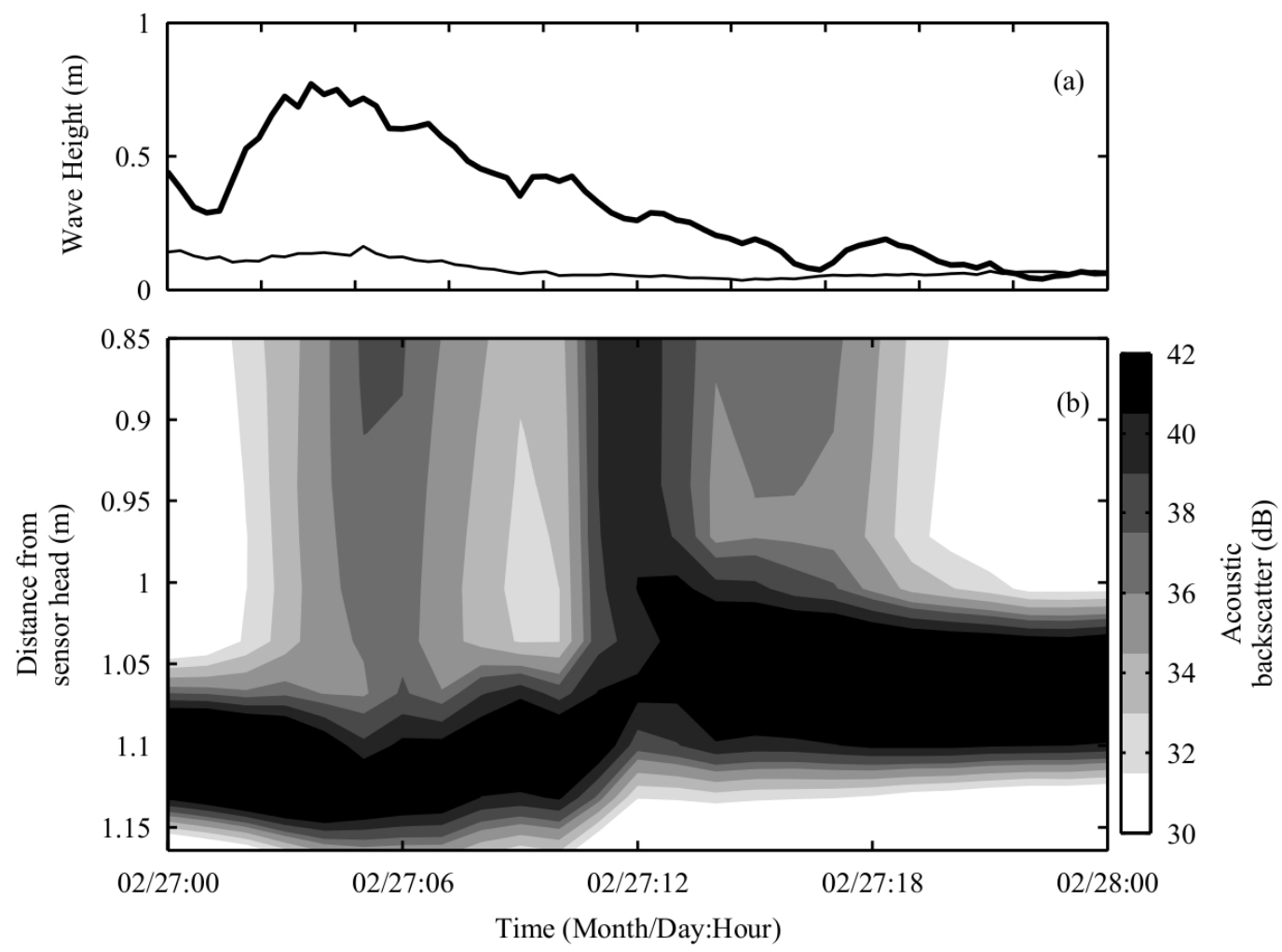

Figure 3. Wave conditions and bed position indicators and state during the storm of February 27th (a) Significant wave height (short-wave: thick line, swell: thin line). (b) PC-ADP acoustic backscatter intensity.

\section{WATER COLUMN PROCESSES}

The vertical distribution of SSC was reconstructed both by calibrating the acoustic backscatter intensity of the PC-ADP and numerically. The numerical model also provided the evolution of the bottom shear stress throughout the period investigated.

The conversion algorithm for reconstruction of SSC profiles from PC-ADP backscatter profiles assumes a floc size independent of depth and applies a method given by Sahin et al. (under review) in two steps: a) a procedure for estimation of the PC-ADP system constant, and b) an optimization search for a depth-independent, "effective" floc size, corresponding to the best fit between backscatter and optical SSC estimates. The range dependence of acoustic backscatter was corrected for attenuation due to water and sediment, and spherical spreading using the algorithm given by Thorne and Hanes (2002). Because the system constant did not show sensitivity to floc size in previous applications (e.g., Sahin et al. under review, Sahin et al. 2012), a constant floc size of $200 \mu \mathrm{m}$ was used in calibration which is the consistent peak of the size distribution of previously collected data (Safak et al. 2010). After determining the calibration constant, the effective floc size corresponding to the best fit between the PC-ADP estimates and measurements from the optical sensors was searched in the range between 50 $\mu \mathrm{m}$ and $350 \mu \mathrm{m}$ based on previous floc size measurements (Safak et al., 2010). The details of the 
conversion algorithm can be found in Sahin et al. (under review). The PC-ADP was calibrated using the OBS measurements at two vertical points between February 19th and February 28th. The SSC profile and the floc size for each burst over the duration of the experiment including the major event of interest were determined. The deviation (RMS error) between the calculated concentrations and the optical measurements was $0.62 \mathrm{~g} / \mathrm{L}$ with correlation coefficient $\mathrm{r}^{2}=0.88$.

The estimated profiles of SSC, together with the measured current profiles, were then used to constrain a 1DV bottom boundary model (Hsu et.al. 2009) in order to calculate bottom shear stresses at different stages of bed reworking cycle. The model integrates the two-phase (fluid and sediment) Reynolds-averaged momentum equations based on a turbulent kinetic energy-dissipation rate of turbulent kinetic energy $(k-\varepsilon)$ closure. The momentum balance is between free-stream horizontal pressure gradient (prescribed as flow forcing due to waves and currents) and momentum transport by fluid shear stresses (both viscous and turbulent). The sediment concentration is balanced between gravitational settling and turbulent mass flux. The effect of sediment on fluid turbulence is accounted for in the turbulence balances by the density-induced stratification due to vertical gradient of suspended sediment concentration. The sediment phase is defined in the model with a primary particle size, floc size, fractal dimension, resuspension coefficient and critical shear stress to initiate sediment motion at the bed, all of which are independent of time and location above the bed (constant floc density and settling velocity). Further details of the numerical model and the governing equations can be found in Hsu et al. (2009).

The model was calibrated using the PC-ADP velocity measurements and the SSC estimates based on the PC-ADP backscatter, and was run using the relaxation time method which generates a mean current profile with a user-defined depth-averaged velocity. The oscillatory part of the flow was defined in the model as a sinusoidal wave with the period and variance derived from PC-ADP observations. In simulations, the floc size was varied between $50 \mu \mathrm{m}$ and $350 \mu \mathrm{m}$ (density between $1,100 \mathrm{~kg} / \mathrm{m}^{3}$ and $1,350 \mathrm{~kg} / \mathrm{m}^{3}$ ). Because the model uses a no-flux boundary condition at the top of the model domain, resulting in local concentration values close to zero, the top of the model domain was set to $22 \mathrm{~cm}$ above the first PC-ADP cell ( 1-m model domain). This allowed the model to match the concentration estimates at the first PC-ADP cells. The SSC profiles and bottom stresses calculated using the bottom boundary-layer numerical model are shown in Figs. 4b and 4c, respectively.



Figure 4. Model simulations for the storm of February 27th to 28th. (a) Significant wave height (short-wave: thick line, swell: thin line). (b) Numerically estimated SSC vertical structure. (c) Numerically computed bottom shear stresses at the bed level. 


\section{RESULTS}

The numerical model results (Figs. $4 \mathrm{~b}$ and $4 \mathrm{c}$ ) suggest that the amount of the sediment in the water column is controlled by the variations in the bottom stress. The shear stress values are less than $0.3 \mathrm{~Pa}$ during low wave-current activity periods. The two significant resuspension events coincide with two clear peaks in the modeled bottom stress, with a maxima at around 0.6 Pa. The first event appears to have triggered the bed erosion process that started in the morning of February 27th, when the simulated shear stress is in the range of $0.3 \mathrm{~Pa}$ to $0.5 \mathrm{~Pa}$. This erosional critical shear stress range remarkably supports the findings suggested by Sahin et. al (2012).

Time evolution of the bed density is estimated based on the vertical mass balance between the water column and the bed (ratio between the volume that the sea-floor gains/loses and the mass that the water column loses/gains), except the periods when both the bed and the water column gain/lose sediment which is a clear indicator of sediment entering the domain from another source (Atchafalaya River discharge in this case, Fig. 5c). Similar to previous results (Sahin et. el. 2012), the values indicate a softening in early stages of erosion, and increase in density after February 27th 10:00 hours since the bed layers become stiffer (critical shear stress is also increasing) with depth. The bed density values show a steady increase with hindered settling, past the gelling point $\left(\rho_{g e l}=1100 \mathrm{~kg} / \mathrm{m}^{3}\right)$ during consolidation.
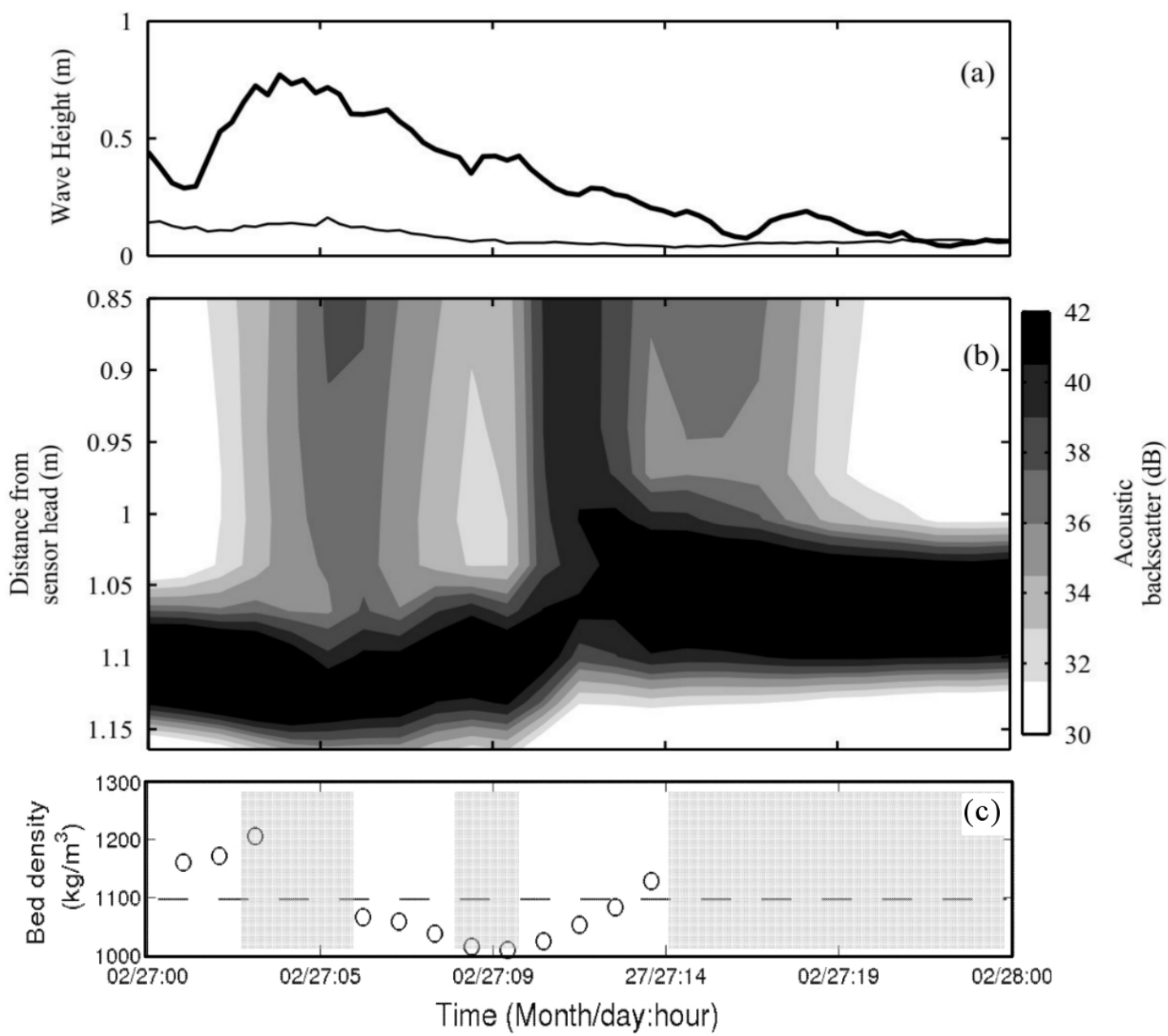

Figure 5. A summary of the bed reworking cycle during the storm of February 27th to 28th. (a) Significant wave height (short-wave: thick line, swell: thin line). (b) PC-ADP acoustic backscatter intensity. (c) Density of the removed/deposited bed layers estimated directly based on a mass balance. In (c), grey hatched areas cover the periods where the density values are invalid. 


\section{SUMMARY}

The relation between the cohesive bed sediment processes and the hydrodynamics is investigated in detail using the observations made in late February 2008 on the muddy Atchafalaya Shelf, Louisiana.

Estimates of vertical structure of sediment concentration and boundary layer model compuations of near-bed flow parameters (bottom shear stress) have been interpreted together in order to generalize the results of a previous study (Sahin et. al 2012). During both storms (storms of March 3rd to 5th in Sahin et al. 2012, and February 27th herein), the bed evolution showed a similar bed reworking cycle of: 1) resuspension, 2) erosion; 3) deposition/accretion; 4) fluid mud formation; 5) consolidation.

The variation of the bottom stress driven by waves and currents plays a major role in mobilization of the bed sediment. Results on the bottom stress-resuspension relation, critical shear stress for erosion and bed density variation throughout the storm remarkably supported the previous findings. The results are encouraging for building a statistical model for the bed reworking cycle (liquefaction, erosion, fluidmud formation and consolidation processes) and represents a step toward a forecasting model for wavebed coupling in muddy environments. Similar analyses for a larger number of storm conditions at different water depths should be the focus of the future efforts.

\section{ACKNOWLEDGMENTS}

This research was supported by the Office of Naval Research funding of contracts N00014-10-10363, N00014-10-1-0805, and N00014-11-1-0269. The corresponding author acknowledges the Council of Higher Education, Turkey and the Yildiz Technical University for the scholarship offered during his doctoral study. The authors wish to thank Prof. A.J. Mehta for his suggestions and advices about mud dynamics. We are grateful to Prof. T-J. Hsu for providing the numerical model for the simulations.

\section{REFERENCES}

Allison M.A., G.C. Kineke, E.S. Gordon, and M.A. Goni. 2000. Development and reworking of a seasonal flood deposit on the inner continental shelf off the Atchafalaya River, Cont. Shelf Res., 20, 2267-2294.

Hsu, T.-J., C.E. Ozdemir, and P.A. Traykovski. 2009. High resolution numerical modeling of wave supported gravity driven mudflows, J. Geophys. Res., 114, C5, doi:10.1029/2008JC005006.

Jaramillo, S., A. Sheremet, M.A. Allison, A.T. Reed, and K.T. Holland. 2009. Wave-mud interactions over the muddy Atchafalaya subaqueous clinoform, Louisiana, USA: Wave-driven sediment transport, J. Geophys. Res., 114, C04002, doi: 10.1029/2008JC004821.

Kineke, G.C., E.E. Higgins, K. Hart, and D. Velasco. 2006. Fine-sediment transport associated with cold-front passages on the shallow shelf, Gulf of Mexico, Cont. Shelf Res., 26, 2073-2091.

Safak, I., A. Sheremet, M.A. Allison, and T.J. Hsu. 2010. Bottom turbulence on the muddy Atchafalaya Shelf, Louisiana, USA, J. Geophys. Res., 115, doi:10.1029/2010JC006157.

Safak, I., C. Sahin, J.M. Kaihatu, and A. Sheremet, under review , Modeling wave-mud interaction on the central chenier-plain coast, western Louisiana Shelf, USA.

Sahin, C., I. Safak, A. Sheremet, and A.J. Mehta. 2012. Observations on cohesive bed reworking by waves: Atchafalaya Shelf, Louisiana, J. Geophys. Res., doi:10.1029/2011JC007821.

Sahin, C., I. Safak, T.-J. Hsu, and A. Sheremet. under review. Observations of sediment stratification on the muddy Atchafalaya Shelf, Louisiana, USA.

Sheremet A., and G.W. Stone. 2003. Observations of nearshore wave dissipation over muddy sea beds, J. Geophys. Res., 108, C11, 24, doi: 10.1029/2003JC001885.

Sheremet A., A.J. Mehta, B. Liu, and G.W. Stone. 2005. Wave-sediment interaction on a muddy inner shelf during Hurricane Claudette, Est. Coas. Shelf Sci., 63, 225-233.

Sheremet A., S. Jaramillo, S.-F. Hsu, M.A. Allison, and K.T. Holland. 2011. Wave-mud interactions over the muddy Atchafalaya subaqueous clinoform, Louisiana, United States: Wave processes, $J$. Geophys. Res., 116, C06005, doi: 10.1029/2010JC006644.

Thorne, P.D., and D.M. Hanes. 2002. A review of acoustic measurement of small-scale sediment processes, Con. Shelf. Res., 28, 309-317.

Traykovski, P., P.L. Wiberg, and W.R. Geyer. 2007. Observations and modeling of wave supported sediment gravity flows on the Po prodelta and comparison to prior observations from the Eel shelf, Cont. Shelf Res., 27, 375-399. 